\title{
Nesting the taxonomy in the remedial: a re-examination of promissory terms
}

\author{
Carol G S TAN
}

\author{
School of Law, School of Oriental and African Studies, \\ University of London*
}

\begin{abstract}
Introduction
The area of contract law doctrine identifiable by the terms "condition", "warranty"1 and "innominate term" - promissory terms - has retained an unsettled feel. This is partly a function of the relative newness of some of its caselaw. The Court of Appeal's decision in Hong Kong Fir Shipping Co. Ltd v Kawasaki Kisen Kaisha Ltd ${ }^{2}$ dates from 1961 yet, as observed in 1995, compared to other parts of contract law, such as the formation of contract, this was then "almost the day before yesterday". 3 Added to the passage of this relatively short period of time is the fact that in the common law jurisdictions of Singapore and Australia, Hong Kong Fir was only recently considered at appellate level. ${ }^{4}$ Furthermore, it is apparent that scholars and judges have held different views on a variety of questions pertaining to this area of the law. These include what was decided in Hong Kong Fir ${ }^{5}$ whether this case introduced a new type of term or merely brought to our attention a pre-existing principle; ${ }^{6}$ if the latter, what the rule is; and how many types of promissory term exist today to name
\end{abstract}

The author thanks SOAS students Edmond Fung and Benjamin $\mathrm{Ng}$ for their research assistance.

1 In this article "condition" and "warranty" are used in their technical sense as promissory terms and exclude the meaning of "warranty" in insurance contracts.

2 [1962] 2 QB 26.

3 J Bird, R Bradgate and C Villiers (eds), Termination of Contracts (London: Wiley Chancery 1995), p. 8.

4 See nn. 8 and 9 below.

5 See, e.g. M Furmston, Cheshire, Fifoot and Furmston's Law of Contract 15th edn (Oxford: OUP 2006). For a discussion of other uncertainties over Hong Kong Fir see J W Carter, G J Tolhurst and E Peden, "Developing the intermediate term concept" (2006) 22 J Cont L 268-9, which has a section titled "What did Hong Kong Fir decide?"

6 One not uncommon rendering of the law is that until the introduction of the intermediate term in Hong Kong Fir, there were only two types of promissory term. Lord Diplock in Hong Kong Fir itself presented it as a rediscovery of principles that had already been applied in earlier cases and Lord Denning in Cehave NV v Bremer Handelsgesellschaft mbH, The Hansa Nord [1976] QB 44, at 60, referred forcefully to the many cases on the intermediate term that stretched continuously from Boone v Eyre (Note) 1 Hy BL 273 to Mersey Steel and Iron Co. Ltd v Naylor, Benzon and Co. (1884) 9 App Cas 434. See the very compelling arguments on the historical development of the law in D Nolan, "Hong Kong Fir Shipping Co. v Kawasaki Kisen Kaisha Ltd, The Hong Kong Fir (1961)" in C Mitchell and P Mitchell (eds), Landmark Cases in the Law of Contract (Oxford: Hart Publishing 2008), pp. 269-98. The discussion there shows that the concern for the consequences of the breach in determining the right of the injured party to terminate the contract in Hong Kong Fir is a continuation of a line of cases stretching back to the cases allowing termination based on the concept of the condition precedent. 
but a few. There have also been normative arguments, particularly over contending values or ideals. Indeed, one common law jurisdiction considered rolling back the developments of the preceding few decades by collapsing the condition, warranty and innominate term into a single term. ${ }^{7}$

Many of the arguments in this area of the law have involved dichotomies of oppositional pairings. Each side of the pairing is presented as a threat to the other: increase in support for one necessarily diminishing support for the other. Thus, we have often heard arguments between "construction" and "breach"; between "nature of the term" and "seriousness of the consequences that follow the breach"; between ab initio and "wait-andsee" approaches; and between "predictability" and "fairness". The recent decisions from Singapore and Australia - RDC Concrete Pte Ltd v Sato Kogyo (S) Pte Ltd ${ }^{8}$ and Koompabtoo Local Aboriginal Land Councilv Sanpine Pty $L t d^{9}$ respectively - continue this trend but also provide clarity on the position of the ostensibly opposing values. ${ }^{10}$ Most of the oppositional pairings mentioned above can be accommodated in the dichotomy of "certainty" and "fairness". This is indeed the pairing that has dominated discussion since Hong Kong Fir and, as we shall see, is part of the Singapore Court of Appeal's "integrated" scheme in RDC. In this article, I argue that the narrow lens through which the dichotomy of certainty and fairness has been discussed in this context has obscured from view two different perspectives on the question of when, in the face of a breach of contract, the injured party is allowed to terminate the contract. The perspective, which I call the "taxonomic" perspective, emphasises a rational and orderly taxonomy of promissory terms and aspires to a schema in which each category of term is invested with a unique characteristic or consequences unique to that category sufficient for each category to be differentiated from the other two. The "remedial" perspective, by contrast, treats any taxonomy of terms as subsidiary, being chiefly interested in the question of remedies for breach of contract and in particular the question of whether the party not in breach may terminate for that breach. ${ }^{11}$ The confrontation between these two approaches provides a better vantage point from which to understand the accommodation of the competing values of certainty and fairness, to appreciate the solution reached in $R D C$ and to explore refinements to it.

\section{The filing cabinet and the China Sea}

As already mentioned, debates in the law concerning promissory terms have been conducted on the basis of a binary opposition between certainty, whose importance in commercial cases is often stressed, and fairness. Fairness, in this context, has usually meant remedial fairness, that is commensurability between the breach and the remedy. The capacity to determine the remedy so that it is proportionate to the breach explains why it has been referred to as remedial flexibility. Fairness is also often judged to include some aspects of the idea of good faith so that the injured party, for example, should not be allowed to take advantage of a breach causing little prejudice (sometimes referred to as a "technical breach") in order to terminate the contract. Certainty, on the other hand, privileges any approach or rule that increases predictability in the rights of the injured party after a breach

7 The Law Reform Commission of New South Wales suggested this for the law relating to the sale of goods in a working paper: see Working Paper on the Sale of Goods (1975), discussed in J W Carter and C Hodgekiss, "Conditions and warranties: forebears and descendants" (1977) 8 Sydney LR 31-67, pp. 63ff.

8 [2007] 4 SLR 413. Also reported in [2007] SGCA 39; 115 ConLR 154.

9 (2007) 241 ALR 88; [2007] HCA 61; (2008) 82 ALJR 345.

10 For an article discussing both cases, see J W Carter, "Intermediate terms arrive in Australia and Singapore" (2008) 24 J Cont L 226-50.

11 Cf. Nolan, "Hong Kong Fir", n. 6 above, which uses a more historically rooted analysis to arrive at a similar view of the law being a contest between two approaches. 
has occurred. One typical version of the argument puts on one side of this opposition the approach that privileges the nature of the term. In its extreme form, this approach demands an exhaustive division of promissory terms into the categories of either condition or warranty and is thus referred to here as the twofold approach. ${ }^{12}$ Although there will be situations in which it is not clear whether a term is a condition or a warranty, this does not in any way diminish the fact that a term is either a condition or a warranty. The central value attached to the twofold approach - whether it was ever an accurate description of the law - and the root of its appeal in the eyes of its proponents, is that of certainty. The injured party may not in the event choose to terminate the contract, yet the twofold approach is said to serve the need for certainty better because whether the injured party has the right to terminate upon breach can be ascertained from the outset of the contract by looking at the nature of the term, including any nature ordained by statute or precedent, and in the absence of that, by way of construction of the terms of the contract. Thus, writing in 1976 after Cehave NV v Bremer Handelsgesellschaft mbH, The Hansa Nord, ${ }^{13}$ a case in which the Court of Appeal relied on its own decision in Hong Kong Fir, Tony Weir observed:

Under the old dispensation, when the right to reject depended on the nature of the term in the contract which was broken, the innocent party simply had to go to the filing-cabinet, consult the contractual document and then decide whether the term broken was a very serious one or not; this final step admittedly called for judgment, and there could often be two views, but at any rate the requisite data were immediately and presently available. Now that the right to resile turns on the gravity of the consequences of the breach, the necessary data are not words but events, they may be in the China Sea rather than in the head office where decisions are taken, and one will probably have to wait for them, since consequences tend to occur, after their cases; nor has the difficulty of assessment been alleviated, rather the reverse. There has therefore been an undeniable loss of speed and sureness of decision-making, and the Court of Appeal is responsible for it. This is a matter of regret. . ${ }^{14}$

The breach of a term and its consequences may, under "the old dispensation", be a part of the consideration of the "nature of the term" but only as an abstraction; the courts may consider the consequences likely to occur if the term in question were to be breached, but it is not the actual breach which has occurred - not the events "in the China Sea" that are taken into account.

On the opposite side of this pairing is the approach that takes into account the consequences that have in fact flowed from the breach. This is the approach in Hong Kong Fir where, it will be remembered, there had been a breach of the term that the vessel should be "seaworthy". In disposing of the appeal, the Court of Appeal stated that with a term such as this, regard must be had to the consequences of the breach. The seaworthiness term

12 As we shall see, this approach is not the same as the more limited "condition-warranty" approach as it is identified by the Singapore Court of Appeal in $R D C$.

13 [1976] QB 44.

14 T Weir, "The buyers' right to reject defective goods" (1976) 35 CLJ 33-8. In The Hansa Nord, the Court of Appeal had overturned the finding that the delivered goods were unmerchantable but found that there was a breach of the express term that the goods be "shipped in good condition". As an express term, the term was not within the scope of the Sale of Goods Act. This enabled the Court of Appeal to find that the term was an innominate term and, thus, whether the injured party could terminate the contract depended on the consequences of the breach. In the passage quoted in the text, Weir is primarily criticising the Court of Appeal for extending Hong Kong Fir to contracts for the sale of goods. In his opinion, in sale of goods contracts, the common law principles on the innominate term should have no application since the Act specifically deals with the promissory terms in one of two categories - conditions and warranties. Weir acknowledged that "the doctrine of the Hong Kong Fir case ... was welcomed widely and enthusiastically". 
could be broken in a number of ways and with consequences that could be trivial or serious. Whether the charterer was permitted to terminate the contract would therefore depend on the seriousness of the consequences of the particular breach that had occurred. ${ }^{15}$

Leaving aside the question of whether this was an introduction or a re-introduction of legal principle, relevant to the question of certainty and fairness, we should note that the Court of Appeal is accused of introducing uncertainty with its decision in Hong Kong Fir because, instead of permitting the parties to know from the outset that in the event of a breach of a term the injured party may terminate (in the case of a condition) or that the injured party may not terminate (in the case of a warranty) following a breach, both parties must wait and see as the consequences unfold. In practice, there will be difficulty in assessing whether the events are sufficiently serious to entitle the injured party to terminate the contract and the attendant risk of wrongful termination. For the loss of certainty, however, fairness is gained because the right to terminate only arises when the events are sufficient to warrant termination. In this context, sufficiency may also act as a proxy for reasonableness: when termination is warranted because the consequences are sufficiently severe, this will usually coincide with it being reasonable for the injured party to terminate the contract. Reasonableness, in turn, can be seen as an aspect of fairness. ${ }^{16}$ Whatever the disagreements are as to the precise formula and required standard of severity or reasonableness, it is clear that the approach in Hong Kong Fir requires an assessment, not of the importance of the term that has been breached, but of the consequences of the breach - sometimes referred to as the "event" or "events" which have taken place as a result of the breach.

These models, in which the twofold approach and Hong Kong Fir are associated with certainty and fairness respectively, have been presented here with their features exaggerated so as to emphasise the difference between them. As straw men, the impression they give of mutually exclusive association with either certainty or fairness is easily assailed. The following statements provide a flavour of the deconstructive arguments that can be made in this context:

1) the twofold approach offers less certainty than appears at first glance because whether a term is a condition or a warranty will often be unclear;

2) certainty and fairness are not in fact opposites - certainty can be viewed as a species of fairness since being able to predict the possible outcome enables the parties to make arrangements for the various risks entailed by their entry into the contract;

3) in the twofold approach, a court is meant to construe the term without taking into account the "events" that have by this time taken place including, as may be the case, the actual motive of the party that has terminated the contract in response to the breach by the other side. A judge, when shown the contract which has been retrieved from the filing cabinet may well find it impossible to prevent any knowledge already gained of the events in the China Sea from influencing the conclusion as to whether the injured party should be allowed to terminate.

These sorts of arguments indicate that certainty and fairness do not constitute a logical contradiction; while remaining distinct, traces of one are to be found in the other. For present purposes, these comments are sufficient to show that Hong Kong Fir, while it may

15 Hong Kong Fir Shipping Co. Ltd v Kawasaki Kisen Kaisha Ltd [1962] 2 QB 26.

16 R Brownsword, "Bad faith, good reasons and termination of contracts", in Bird et al., Termination of Contracts, n. 3 above, pp. 227-52. This is a revised version of "Retrieving reasons, retrieving rationality? A new look at the right to withdraw for breach of contract" (1992) 5 J Cont L 83107 by the same author. 
have added to the opportunities for uncertainty, did not introduce uncertainty. The choice is therefore less stark than portrayed in the models set out earlier or as imagined, for instance, by Weir. In spite of these observations, it remains possible to say that the twofold approach contains in it a stronger allegiance to certainty than does the approach taken in Hong Kong Fir, in which remedial flexibility is the privileged objective.

As is implied in Weir's dislike of the Hong Kong Fir decision, extreme arguments in favour of certainty would support a division of all promissory terms into conditions and warranties. This is thought to be because it is only in this way that the answer to the question of whether, in the event of a breach, the party not in breach may terminate can be answered at the outset of the contract. On the other hand, extreme versions of the argument favouring remedial fairness would prefer extensive or even exclusive use of the Hong Kong Fir approach so that the remedy and the breach or its consequences are commensurate. ${ }^{17}$ As the two approaches are imagined to be locked in a zero-sum game, judges and others have either counselled for or against the liberal application of Hong Kong Fir.

In order to appreciate the improved clarity in the law offered by the Singapore Court of Appeal, we turn next to a few observations regarding the law on promissory terms.

\section{Hong Kong Fir and the law on promissory terms}

In the foregoing section, Hong Kong Fir has for the most part been treated as a decision which provided an approach or a principle on termination which is dependent upon the consequences of the breach. Albeit overlapping with this, Hong Kong Fir has also been treated as authority for a type of promissory term possessing a "complex nature" and thus an "intermediate" term between the two other types. ${ }^{18}$ At least from the time of the Sale of Goods Act 1893, in the general law of contract, the language of the Act has fostered a view of conditions as important terms in a contract and warranties as terms which are less important or "collateral to the main purpose of the contract". ${ }^{19}$ However, at least since Hong Kong Fir, no perfectly ordered hierarchy of terms has existed. For instance, it has been obvious for some time that the typology of terms bears an imperfect relationship to the remedy that is available when the term is breached or to the damage that ensues from a breach. Of the latter, a perfect hierarchy would require that the following set of propositions be true:

1) all breaches of a condition cause serious prejudice;

2) some breaches of an intermediate term cause serious prejudice; and

3) no breaches of warranty cause serious prejudice. ${ }^{20}$

17 For an example of this tendency, see the decision of Slynn J in Tradax International SA v Goldschmidt [1977] 2 Lloyd's Rep 604-12, who was of the view that there should be a leaning in favour of classifying a term as an intermediate term.

18 There is sufficient support for the view that current law acknowledges that "condition", "warranty" and "innominate term" are the three terms of art denoting types of promissory term: see J Beatson, Anson's Law of Contract 12th edn (Oxford: OUP 2002), p. 135, where he states: "Another approach, often seen as more modern but in fact with older roots, rejects the proposition that every term of the contract can be classified as either a condition or a warranty. On this approach there is a third category of intermediate (or 'innominate') terms."; and G Treitel, Some Landmarks of Twentieth Century Contract Law (Oxford: Clarendon Press 2002), at p. 113, where Treitel speaks of a "third type of contract term" in Hong Kong Fir be that one that was therein "invented" or "rediscovered".

19 S. 62 of the Sale of Goods Act 1893, a provision which is retained in the 1979 Act.

20 Treitel, Some Landmarks, n. 18 above, p. 117, points out the impossibility of such a representation of the law. See also his earlier discussion at p. 110 which is based on passages from the judgment of Lord Diplock in Hong Kong Fir. 
Of the former, the following set of propositions would need to be true:

1) termination is available for a breach of a condition;

2) termination may be available for a breach of an intermediate term; and

3) termination is not available for a breach of a warranty.

Neither set of propositions holds water. In the first set, only proposition 2) is unfalsifiable and then only because it is a statement which makes no commitments. The other two are easily defeated. As for the second set, it is clear that if the consequences of a breach of a warranty are sufficiently serious, the injured party will be allowed to terminate the contract. ${ }^{21}$ The first of the propositions in this second set is true in theory but can be side-stepped by construing the term so that it is not, after all, a condition. ${ }^{22}$ While construction is used in the case of what is apparently a condition, where a term which is a warranty is concerned, the technique used to allow termination is to establish that while there may be a prima facie rule that the remedy for a breach of warranty is an award of damages, that rule can be displaced by the application of an external principle (external, that is, to the law on promissory terms) in the form of the doctrine of substantial failure of performance. More will be said of this doctrine below. Meanwhile, these observations suggest that, in practice, in no type of term is there a conclusive relationship between the type of term and the availability of termination. At present, it is sufficient to add that the modern principle that allows termination for a sufficiently serious breach of warranty has been thought to derive from Hong Kong Fir though its resemblance to the doctrine of substantial failure of performance is great. ${ }^{23}$ Related to this is the observation that where the remedial prospects of the injured party are concerned, the warranty appears so similar to the innominate term that the question arises whether there is any merit in retaining the distinction between the warranty and the innominate term. This is another question to which we shall return.

A further point to bear in mind is that the law recognises the intention of the parties where it is made sufficiently clear. Parties can, by express stipulation, provide for a right to terminate for breach of a term even if no serious prejudice is caused to the injured party, including doing so by sufficiently explicit use of the designation "condition", so long as it is used in its technical sense. It should also be open to parties to provide expressly that there is to be no termination in the case of a warranty even if there is serious prejudice. ${ }^{24}$ Furthermore, some terms, by the operation of precedent, have or will become recognised by the courts as being of commercial importance. This is what was meant by Lord Roskill in Bunge Corp. v Tradax Export $S A$ when he remarked that there were:

$[\mathrm{M}]$ any cases ... where terms the breaches of which do not deprive the innocent party of substantially the whole benefit which he intended to receive from the

21 See the judgment of Ormrod LJ in The Hansa Nord where the point is grounded on an application of Hong Kong Fir. RDC Concrete Pte Ltd v Sato Kogyo (S) Pte Ltd [2007] 4 SLR 413; [2007] SGCA 39 and Koompabtoo Local Aboriginal Land Council v Sanpine Pty Ltd (2007) 241 ALR 88; [2007] HCA 61 adopt much the same position.

22 See n. 14 above on The Hansa Nord. See also Schuler (LG) AG v Wickman Machine Tool Sales Ltd (1974) AC 235 where the majority of the Court of Appeal took the view that the parties could not have intended to use the word "condition" in its technical sense.

23 See n. 21 above.

24 In the context of the law in Singapore, this was urged in Gao Yihan, "Towards a consistent approach in breach and termination of contract at common Law: RDC Concrete Pte Ltd v Sato Kogyo (S) Pte Ltd' (2008) 24 Journal of Contract Law 251-67 and given clear support as a principle by the Singapore Court of Appeal: see Phang JA, delivering the judgment of the court in Sports Connection Pte Ltd v Deuter Sports GmbH [2009] 3 SLR(R) 883; [2009] SGCA 22, paras 28ff. 
contract were nonetheless held to be conditions any breach of which entitled the innocent party to rescind. ${ }^{25}$

To summarise the foregoing discussion, the condition, warranty and intermediate term are categories of promissory term which are distinct, yet each term cannot easily be distinguished on the basis of either the remedy that is offered upon breach or the seriousness of the consequences which would flow from a breach. The principles regarding breach of promissory terms and termination may, however, be reduced to a set of practical rules from which we can assess the approach advocated in $\mathrm{RDC}$. In the absence of the parties' clear intention:

1) when a condition has been breached, the injured party has the option to terminate the contract;

2) when an intermediate term has been breached, the injured party has the option to terminate if the consequences of the breach are sufficiently serious; and

3) when it is a warranty that has been breached, likewise there is an option to terminate if the consequences of the breach are sufficiently serious.

\section{Decisions from Singapore and Australia}

Significant in RDC Concrete Pte Ltd v Sato Kogyo (S) Pte Ltd ${ }^{26}$ is the decision tree articulated by the Singapore Court of Appeal. According to Phang JA, delivering the judgment of the court, when faced with a breach, once it is clear that the parties have not made their intentions on the matter clear, the question as to whether the injured party has the right to terminate the contract should be dealt with in accordance with the following steps. ${ }^{27}$

1) The first question to be asked is whether the term that was breached is a condition. If it is, the injured party may terminate the contract.

2) If the term is not a condition, the court should look at the consequences of the breach. Even if the term is a warranty, the presence of serious consequences would entitle the injured party to terminate.

The Singapore Court of Appeal explained that these steps are driven by two approaches employed consecutively. The first, which the court referred to as the "condition-warranty" approach, involves looking at the nature of the term, rather than at the consequences of the breach. This condition-warranty approach should not be confused with the twofold approach discussed above. The intent of the Singapore Court of Appeal is that the condition-warranty approach is only one part of its integrated approach; the twofold approach, in contrast, was intended to represent the entirety of the principles which link promissory terms and termination. The condition-warranty approach, according to

25 [1981] 1 WLR 711 at 724. Arguably, s. 15A of the Sale of Goods Act, introduced by s. 4(1) of the Sale and Supply of Goods Act 1994, is an acknowledgment that breaches of conditions can result in trivial consequences (for which termination would not be a reasonable remedy, consumers excepted). The section refers to a breach by the seller that is "so slight that it would be unreasonable for the buyer to reject the goods" where the buyer is a non-consumer.

26 See n. 8 above.

$27 \mathrm{RDC}, \mathrm{n} .8$ above, paras $89 \mathrm{ff}$. Only the part of the decision tree relevant to the present discussion is mentioned here. The decision tree of the court (also discussed in a lecture delivered by the same Singapore Judge of Appeal, A Phang, "Doctrine and fairness in the law of contract" (2009) 29 Legal Studies 534-75, pp. 546ff) is provided in the form of a helpful table by the court. See also Man Financial (S) Pte Ltd (formerly known as ED \& F Man International (S) Pte Ltd) v Wong Bark Chuan David [2008] 1 SLR 663 where the Singapore Court of Appeal repeated the scheme of the law in very similar terms. See also the addition made in Sports Connection mentioned in n. 24 above. 
Phang JA, is conclusive only if, upon applying it, the term is found to be a condition. When the term is found to be a warranty, the second approach - the Hong Kong Fir approach becomes relevant. We should note that in $\mathrm{RDC}$, although the phrase "innominate term" is used, Hong Kong Fir is almost exclusively treated as an approach or principle which allows for termination for a sufficiently serious breach of a term which is not a condition. As such, it poses a large threat to the condition-warranty approach and, according to the Singapore Court of Appeal, this threat is resolved by giving each a sequential role. ${ }^{28}$

Although the High Court of Australia was not referred to $R D C$, the approach of that court bears some similarities to the approach presented in $\mathrm{RDC}$. One of the key points made by the majority of the court in its joint reasons (Gleeson CJ, Gummow, Heydon and Crennan JJ), and for agreeing with the trial judge, was that whether the injured party had a right to terminate after a breach was first a question of construction of the contract. This would include both where the parties have provided expressly for termination following breach and also where the parties intended that the term that has been breached is a condition. While accepting a tripartite classification of promissory terms in which the intermediate term is placed amongst terms which were non-essential, the main distinction that was considered was between conditions and non-conditions (also referred to as "essential" and "non-essential" terms). According to the joint reasons, if a term is an essential term, the injured party has a right to terminate the contract. If the term is a nonessential term, termination will be allowed if there is a sufficiently serious breach. Only Kirby J disagreed with the reception of the intermediate term into the common law of Australia. ${ }^{29}$ Thus, in line with the Singapore Court of Appeal, the majority in the High Court of Australia accepted the applicability of Hong Kong Fir as a principle concerning termination. Furthermore, similar to $R D C$, the joint reasons do not offer a clear distinction between the warranty and the intermediate term.

From a pragmatic, decision-making perspective, the decision of the Singapore Court of Appeal in $R D C$ is welcomed. At least four observations can be made about the decision tree proffered in $R D C$. First, it appears to privilege certainty in that the recommended decision procedure is to be applied only if the parties have not expressed any intention as to whether a breach of a term is to lead to termination. ${ }^{30}$ The importance of certainty is also shown through the recognition that once a term is a condition, the right to terminate the contract following a breach exists without any enquiry into the seriousness of the breach. It is only when this possibility is exhausted that fairness in the sense of remedial flexibility is allowed to operate. The Singapore Court of Appeal was keen to point out that the Hong Kong Fir approach was to be engaged only at this second stage of the enquiry. Second, in the RDC approach, the main concern is to mark out the condition clearly; it supports the suspicion that, parties' intention aside, the line dividing a warranty from an intermediate term is faint. Third, we should note that the decision procedure gives the impression that its application can produce an answer to the termination question when it is more accurate to observe that there remains room for judicial manoeuvre. For example, the standard required to determine whether a breach is considered to be sufficiently serious is subject to debate and variation, and even if governed by an agreed formula or test, will remain a question of fact to be decided in each case. The balance between certainty and fairness can still be adjusted

28 This position appears more clearly in Sports Connection Pte Ltd v Deuter Sports GmbH, see n. 24 above, paras $31 \mathrm{ff}$.

29 Kirby J dissented on this point (but not on the conclusion that the appeal should be allowed), favouring the greater simplicity of a law whose only division is that between "conditions" and "other terms" (para. 108); once it is established that it is a non-essential term that has been breached, the consequences of the breach should be looked at without any further classification of the term. 
in favour of fairness by inventive judges if they are determined to reach the Hong Kong Fir stage of the $R D C$ decision tree. This will affect the balance between certainty and fairness because effectively, the second question may be reached more often than not and, if this is the case, more cases will be subject to the Hong Kong Fir approach than to the condition-warranty approach. Fourth, the Singapore Court of Appeal, in reviewing this area of the law, provided no explanation of the basis for allowing termination for a sufficiently serious breach of a warranty. ${ }^{31}$

\section{Taxonomic and remedial perspectives}

The discussions examined above - the certainty versus fairness debate and the two stages of the integrated $R D C$ approach - are premised upon the assumption of conflicting approaches in competition over the same area of the law. This is clearest in the passage from Weir cited above, but it is also present in the $R D C$ approach and the concern expressed by the same court in Sports Connection that neither the Hong Kong Fir nor the condition-warranty approach should be given free reign as each is capable of "effacing" the other. Each needs to be given "legal space". 32 The principles that have emerged regarding promissory terms, however, are more accurately seen as being located alongside other principles and doctrines. It is the potential conflict and resulting accommodation between promissory terms and other principles of the law over the consequences of a breach that is critical for an understanding of this area of the law.

When taking this broader view, the two perspectives mentioned earlier - taxonomic and remedial - offer a useful handle. Each has its own starting point. From a taxonomic perspective, the main concern is with the types of promissory term - the definition of each type of term and its conceptual identity so that every promissory term can be identified as a condition, warranty or innominate term. By whatever means the words "condition" and "warranty" became terms of art denoting types of promissory term, those with taxonomic tendencies would have been greatly encouraged by the Sale of Goods Act to see conditions and warranties presented therein as separate types of contractual term. Not only did the provisions of this Act distinguish between the two types of term by reference to their relative importance to the contract, they also differentiated the two types of term by providing the buyer of goods with a different permitted response when a breach occurs. So the buyer of goods is allowed to reject the goods if the breach is of a condition but not if the term is merely a warranty. ${ }^{33}$ When the Court of Appeal delivered its judgment in Hong Kong Fir, taxonomists were presented with a third type of term, which was very different from both the condition and the warranty. This term could not be a condition or a warranty in accordance with the important/collateral distinction because the term "seaworthiness" is in fact an umbrella term sheltering a collection of obligations of varying importance, any

31 Andrew Phang has since explained that termination for such a breach is available as one example of how contract law, through its doctrines, achieves outcomes which are substantively fair. Hong Kong Fir is a case which identifies the "tipping point" after which substantive fairness is pursued by the law more directly, in that, even where a term is a warranty, severe consequences would lead to termination being allowed because it is here that we see substantive fairness trumping the sanctity of a contract: Phang, "Doctrine and fairness", n. 27 above.

32 Sports Connection Pte Ltd v Deuter Sports GmbH, see n. 24 above, para. 36. See also paras 34 and 35 for the treatment of Hong Kong Fir as an approach.

33 Note how Carter has shown that, although the Sale of Goods Act was for a long time thought to have codified existing law, this part of the Act was based on the drafter's misunderstanding of the pre-existing law. See Carter and Hodgekiss, "Conditions and warranties", n. 7 above. 
one of which if not performed or fulfilled is a breach of that term. ${ }^{34}$ As Lord Diplock explained in a well-known passage:

[T] he shipowners' undertaking to tender a seaworthy ship has, as a result of numerous decisions as to what can amount to "unseaworthiness," become one of the most complex contractual undertakings. It embraces obligations with respect to every part of the hull and machinery, stores and equipment and the crew itself. It can be broken by the presence of trivial defects easily and rapidly remediable as well as by defects which must inevitably result in a total loss of the vessel. ${ }^{35}$

One main difference lay in the prominence given, in a breach of this third type of term, to the consequences of the breach. As can be seen from the criticisms made by Weir mentioned above, this third type of term is, on the taxonomic view, an incursion into the territory occupied by the condition and the warranty in that every term that is an innominate term cannot, thereby, be a condition or a warranty. As we saw above, because the intermediate term looks at the seriousness of the breach rather than the term's importance to the main purpose of the contract, it was seen as introducing fairness at the expense of certainty. Importantly, however, from a taxonomic perspective, Hong Kong Fir itself provided a definition of the term which was based on its complex nature - this definition gave it conceptual distinctiveness. Taxonomists would naturally have looked to the following passage in Lord Diplock's judgment as being amongst the most important aspects of the Hong Kong Fir decision:

There are, however, many contractual undertakings of a more complex character which cannot be categorized as being "conditions" or "warranties" .. Of such undertakings all that can be predicated is that some breaches will and others will not give rise to an event which will deprive the party not in default of substantially the whole benefit which it was intended that he should obtain from the contract; and the legal consequences of a breach of such an undertaking... depend on the nature of the event to which the breach gives rise and do not follow automatically from a prior classification of the undertaking as a "condition" or a "warranty".36

The implication that it can be predicted that all breaches of a condition will lead to serious consequences and that all warranties will not was made express when Lord Diplock said:

No doubt there are many simple contractual undertakings ... of which it can be predicated that every breach of such an undertaking must give rise to an event which will deprive the party not in default of substantially the whole benefit which it was intended that he should obtain from the contract... So too there may be other simple contractual undertakings of which it can be predicated that no breach can give rise to an event which will deprive the party not in default of substantially the whole benefit which it was intended that he should obtain from the contract. ${ }^{37}$

The flaw in these remarks concerning all breaches of a condition leading to serious consequences and the corollary in the case of the warranty has already been discussed. Here, we note the strong indication that the intermediate term was meant as a type of term

34 As Michael Furmston has observed, the seaworthiness clause is "so heterogenous a clause" that "it might perhaps have been helpful to regard the undertaking of 'seaworthiness', not as a single term, but as a bundle of obligations of varying importance", Cheshire, Fifoot and Furmston, n. 5 above, p. 191.

35 Hong Kong Fir, 71.

36 Ibid. 70.

37 Ibid. 69. 
that is neither a condition nor a warranty. Furthermore, prior to these remarks, Lord Diplock had already addressed directly the argument of counsel for the charterer that the two types of term mentioned in the Sale of Goods Act represented an exhaustive list of the types of promissory term by saying that this was "by no means true of contractual undertakings in general at common law".38

For taxonomists, the passages of Lord Diplock's judgment mentioned above provide encouragement because they point towards a tripartite taxonomy of promissory terms which, while not completely conceptually free from difficulties, is of some consequence when it comes to the question of termination for breach. ${ }^{39}$ The fact that, for the purposes of disposing of the appeal, there was no need to explore the question of into which category of term seaworthiness fell ${ }^{40}$ adds cogency to the argument that Lord Diplock was thinking of a classification of terms, and a tripartite one at that. For remedialists, on the other hand, the basic question is whether the injured party may terminate the contract upon breach. Lord Upjohn's judgment in Hong Kong Fir is illustrative of the remedialist approach; it is framed largely in terms of whether damages would be an adequate remedy for the breach that had occurred. It is in this way that the following passage from Lord Upjohn's statement should be understood:

Where ... on the true construction of the contract, the parties have not made a particular stipulation a condition, it would be unsound and misleading to conclude that being a warranty, damages is a sufficient remedy. ${ }^{41}$

Where the question of whether damages are an adequate remedy is the starting point, the term's classification is only of partial importance and other relevant legal principles will need to be taken into account. Those are, first, that the primary remedy for a breach of contract is the award of damages. This statement would be trite but for the fact that it is often absent from the analysis of cases dealing with promissory terms. Subject to some established exceptions, a fundamental principle of the law of contract assumes that an award of damages will be an adequate remedy. In this light, termination for breach of a contract is allowed only as an exception to this rule. The second relevant principle is the doctrine of substantial failure of performance, under which the injured party is permitted to terminate the contract. As its name suggests, this doctrine allows for termination for breach if the breach amounts to a substantial failure of performance. What amounts to substantial failure has not proven easy to define, but phrases approximating "a breach which substantially deprives a party of the benefit of the contract" or which "goes to the root of the contract" have been used. In some cases, the courts have assessed the breach against the performance of the whole contract to see if the breach is substantial. ${ }^{42}$ As Peel points out, the cases show that a consideration of the inadequacy of damages, whether the party not in breach would be unjustly enriched by the termination, and the likelihood of further

38 Indeed, it is now accepted that the intermediate term applies even in contracts for the sale of goods.

39 This remains arguable even though the phrase "intermediate term" or "innominate term" was not used by Lord Diplock but comes from the head note in the report of the case where the phrase "intermediate stipulation" was used.

40 See the judgment of Sellers LJ in Hong Kong Fir. The appeal could have been disposed of by finding that the breach was insufficient to allow for termination, if necessary, by adding that nothing in previous caselaw had suggested that the seaworthiness term was a condition. This point is made in Carter et al., "Developing the intermediate term concept", n. 5 above. Note also that the authors hint that the issue would simply have been postponed since the seaworthiness term is undeniably one that can be breached in a number of ways.

41 Hong Kong Fir, 62. The attention given specifically to the warranty is explicable when it is remembered that the question does not arise in the case of the condition.

42 Examples often cited include Hong Kong Fir itself, where after repairs to the ship, it was fit to perform the 17 remaining months of the 24 -month charter period. 
breaches, may also be relevant considerations. ${ }^{43}$ In general, while the existence of the doctrine of substantial failure of performance has not been doubted in the cases on promissory terms, yet the interplay of the two has not received adequate attention.

While the effort of the Singapore Court of Appeal to provide a decision tree for the question of termination is welcomed, further developments would assist. To begin with, the decision tree should proceed from a clearer acknowledgment that prima facie, the injured party cannot terminate for breach unless there is a substantial failure of performance. Where there is no such failure, it will be relevant to ask if the term that has been broken is a condition. If it is, the injured party has the choice of terminating the contract, regardless of the seriousness of the breach. ${ }^{44}$ Put in these terms, the decision procedure is a much simplified one. However, it appears to leave no room for any distinction between the intermediate term and the warranty. The only distinction of any significance, which is the position reached in Koompabtoo, is that between conditions and non-conditions.

From a taxonomic perspective, this reduced approach would be disappointing because it would mean relinquishing the tripartite division of terms which, as we have seen, is now established in the law. There are other reasons why we should, with some refinements, salvage the taxonomy of terms and give it a greater role within a more developed scheme. The objective would be to give full recognition to the doctrine of substantial failure of performance while at the same time accommodating the taxonomy of terms in a scheme which is effective for the process of determining whether the injured party is allowed to terminate the contract for breach. In $R D C$, Phang JA explained that the warranty was still distinguishable from the intermediate term because "the spirit behind the concept of the warranty would still remain in appropriate fact situations inasmuch as the innocent party would not be entitled to terminate the contract if the consequences of the breach were found to be trivial". 45

Even taking into account the reinforcements later given to the warranty by the Singapore Court of Appeal in Sports Connection, ${ }^{46}$ the better position is that espoused by Treitel that, whereas there is a prima facie rule that the remedy for breach of a warranty is damages alone, there is no such prima facie rule in relation to the intermediate term. ${ }^{47}$ This idea of a prima facie rule accompanying the warranty could be extended to the two other types of term. In this regard, we might usefully turn to the technique employed elsewhere in contract law in the requirement of intention to create legal relations. There, rather than requiring intention to be established by the party seeking to enforce the agreement, the courts employ one of two mirror-image presumptions depending on whether the agreement is a commercial agreement or a social or domestic agreement. In the former, there is a rebuttable presumption that the parties intended to create legal relations. The opposite presumption applies to social or domestic agreements. Each of the presumptions may be rebutted by evidence to the contrary. Exceptionally, there will be cases which call for a more contextual approach where all relevant facts would be taken into account without

43 E Peel, Treitels Law of Contract, 12th edn (London: Sweet \& Maxwell 2007), pp. 870ff. Notably, this work proceeds on the basis that conditions operate as an exception to the principles regarding the availability of remedies for breach.

44 From the point of view of contracting parties wanting certainty on the question of termination, it may be that asking if a term is a condition should be the first question that is asked, since an enquiry into the seriousness of the breach is avoided if the term is a condition.

45 RDC, n. 8 above, para. 108.

46 See n. 24.

47 Treitel, Some Landmarks, n. 18 above, p. 116. See also p. 125, where a similar point is made in relation to sale of goods contracts. 
the use of a presumption. ${ }^{48}$ In proposing an improved scheme from the one presented in $R D C$, and building upon Treitel's use of prima facie rules, a similar use of presumptions could be made as follows.

1) If the term that has been breached is a warranty, there is a rebuttable presumption that termination is not available. The injured party must prove substantial failure of performance in order to justify termination or be allowed to terminate the contract.

2) However, if the term that has been breached is a condition, the injured party may terminate the contract without establishing that there was a substantial failure of performance. This is to say that there is a conclusive presumption that damages are not an adequate remedy. ${ }^{49}$

3) If the term that has been breached is an intermediate term, there is neither a presumption that termination is available nor a presumption that termination is not available. The court must look at all the circumstances of the case and especially at the consequences of the breach to see if termination should be permitted.

The intermediate term differs from the condition because, in the latter case, the party arguing for lawful termination is in an unassailable position with regard to the right to terminate. It differs from the warranty in that the party wanting to terminate the contract for a breach of a warranty has a heavier burden of proof to shift. In looking at the interaction between the basic rule of damages being an adequate remedy for a breach of contract and its main exception, the doctrine of substantial failure of performance, the condition is the only true exception to that exception. The other two types of term are consistent with the rule on substantial failure of performance but differ between them in the way just pointed out.

What is clear from this scheme is that the taxonomy of terms can play a meaningful role in the question of termination, but only if strengthened by accompanying presumptions in favour of or against termination. When so strengthened, the contribution of the taxonomy of terms lies in the evidential rules attached to each of the types of term.

One final point needs to be addressed. This is the question of whether the Hong Kong Fir approach is one and the same as the doctrine of substantial failure of performance. The two are functionally similar and both allow the consequences of the breach to determine whether termination is permitted. The overlap in the old cases relied on as authority for the doctrine of substantial failure of performance and the cases relied on by Lord Diplock in Hong Kong Fir strongly suggest that the two are one and the same. It is here that the remedialist and taxonomic perspectives offer yet another insight for they cast stronger light on the twin contributions of Hong Kong Fir - an approach and a type of term. The approach is indeed difficult to distinguish from the doctrine of substantial failure of performance. The type of term contribution of Hong Kong Fir can be distinguished from the doctrine of substantial failure of performance and it is this that appears in the taxonomy of terms in the improved scheme suggested here.

\section{Conclusion}

The Singapore Court of Appeal has been concerned to salvage the two approaches that it identified as being a part of current law and also to provide a decision tree which ensured

48 See Edmonds $\mathrm{v}$ Lawson [2000] QB 501.

49 As discussed earlier, construction could be deployed to avoid this situation. 
that neither approach elbowed out the other. There is a similar concern here in that the taxonomy of terms and the remedial principles which have evolved should both be made more effective. By accommodating as fully as possible both the taxonomic and remedial perspectives, whatever be the historical developments through which both emerged, we are able to observe the following. First, rather than privileging certainty, if we "nest" promissory terms in the doctrine of substantial failure of performance, the law in fact privileges remedial fairness. This fairness is then tempered by certainty, rather than the other way around as is presented in $R D C .{ }^{50}$ Furthermore, in this enlarged scheme, certainty is only given a limited role, that is when the term breached is a condition or when the parties have made their intention clear that termination is not an option for breach of a particular term. Beyond these instances, remedial fairness is reasserted. Second, where in $R D C$ the line between the warranty and the intermediate term is still somewhat blurred, in this scheme, the distinction between the two is developed through the use of evidentiary presumptions. Third, the tension between the ideals of certainty and fairness remains as does the room for discretion and for contestation. A judge can still circumvent the conclusive presumption in favour of termination by finding that the term that has been breached is not a condition or, in the case of a breach of a warranty, by finding that the presumption against termination has not been rebutted and, in the case of the intermediate term, finding that taking all the circumstances into consideration, there was no substantial failure of performance. Fourth, the greater attention paid to the doctrine of substantial failure of performance in the suggested scheme explains the asymmetry between the condition and the warranty when it comes to being able to predict the outcome of the question regarding termination.

50 Such an enlarged decision tree would also fit better with Phang's overarching thesis (based on radicalism on which we have not touched in the present article) that contract law pursues substantive fairness: see, Phang, "Doctrine and fairness", n. 27 above. 